\title{
CIM on WHEELS: An Innovative Educational Tool
}

\author{
Lucy Siu-Bik King and Jian Edward Zhang \\ GMI Engineering \& Management Institute
}

\section{Abstract}

CIM on WHEELS is a mini-integrated design and manufacturing, computer controlled laboratory, set up in a trailer with wide-open side and rear doors. The overall dimension for the trailer is $16^{\prime} \times 8^{\prime}$. Observers and operators will be stationed outside the trailer. The equipment and trailer have been purchased with funds from the National Science Foundation (NSF), the Society of Manufacturing Engineers (SME), TRW corporation, GMI matching funds, and contributions from many industrial companies. All equipment, activities and processes are under the supervision and control of a "supervisory" computer. CIM on WHEELS illustrates the concepts of streamlined engineering, from design to process planning to production. The GOAL is to provide a practical media for courses on CIM (computer integrated manufacturing) at GMI, seminars and workshops off-campus at various sectors of the community, technical or academic. The OBJECTIVES for this setup are to provide demonstrations and hands-on experience for students at GMI, for precollege students and for small industrial personnel at off-campus sites. GMI students are required to present,demonstrate and teach the components of CIM which they have learned in class, to offcampus audience. This allows them to obtain a deeper understanding of the topics. It will also give them the opportunity to play mentoring roles to the younger students. The CIM on WHEELS was displayed at SME-AutoFACT '96 Exhibition in Cobo Hall, Detroit, Michigan, November 12-14, 1996.

\section{Introduction}

CIM on Wheels (CIMoW) provides a facility for capstone hands-on projects in the CIM and Robotics courses to enhance the standard of education at GMI and better prepare the graduates for the highly technical, automated work environment of the future. It furnishes an arena for the integration of CIM fundamental principles and technology. "...workers must have a unique mix of competencies, knowledge and skills...", Carnevale states ${ }^{1}$. Educational institutes must "...take the lead in developing new education and training models ... that will keep the American workforce up to world-class standards" ${ }^{2}$. Since manufacturing creates $40 \%-70 \%$ of the real wealth of the nation, the demand for a new breed of manufacturing engineers is high ${ }^{3}$.

The key factor in developing new laboratories and courses is to face the challenge of serious needs for knowledge synthesis and retention of the integration of various disciplines. An integrated multi-disciplinary experience is definitely necessary for today's engineers. Some Japanese higher educational institutions ${ }^{4,5}$ and European colleges and universities ${ }^{6}$ offer such courses at different levels.

There are a number of existing prominant mobile manufacturing laboratories. However, they contain islands of automation. None of them provide integrated hierarchical and sensor feedback control. The National Center for Manufacturing Sciences (NCMS) has a Mobile Lab in which there are NC machines and robots that are driven by computers but the flow from one 
piece of equipment to the next is not existent ${ }^{3}$. University of Tennessee in conjunction with Department of Energy has a mobile unit ${ }^{7}$. There are other similar mobile units referred by $\mathrm{Mr}$. Paul Koontz, President of Denford Computerized Machines \& Systems, Inc., e.g. Technology Leadership Center, London, ON and Jackson Intermediate School District, Jackson, MI. CIMoW is unique. Due to its mobility, $\boldsymbol{C I M o} \boldsymbol{W}$ best provides budding engineers with the opportunity to work with and communicate with people in the community on the subject of integrated manufacturing. Besides, engineers should be brought to relate to people and not just to intricate signs, symbols and machines. "The social context is not someone else's business." 8.

The GMI CIM course covers many individual components of CIM, e.g. robotics, NC machining, process planning \& control and group technology, control by PLC, networking, and input/output (I/O) control (see Appendix A). It also facilitates the configuration of different levels of hierarchical control. The CIM class project integrates design, manufacturing and business functions of making a product. Through teaching with the $\boldsymbol{C I M o W}$, students can better retain what they learned. This paper describes how the objectives are achieved.

\section{Goals and Objectives}

The GOAL is to provide a practical media for courses on CIM (computer integrated manufacturing) at GMI, seminars and workshops off-campus at various sectors of the community, technical or academic. The OBJECTIVES for this setup are to provide demonstrations and hands-on experience for (a) GMI students with state-of-the-art equipment to learn concepts and different disciplines of CIM (computer integrated manufacturing), (b) GMI students to teach what they learned so they are better able to understand and retain the knowledge, (c) pre-college students with incentives to select mathematics, engineering and science careers, (d) GMI students with the opportunity to work with and serve as role models to these younger students, and (e) local small industries with seminars and workshops on CIM. GMI students are able to learn, teach, implement and experience the power of hierarchical computer control of an integrated flexible manufacturing facility with some sensor feedback systems. Subsequently, sharing this experience with other students off-campus using the CIMoW allows the students to become mentors to pre-college students and attract them to choose careers in science, engineering and technology.

\section{Description of CIM on Wheels}

The CIM on Wheels rides in a 16' x 8' trailer ( see Figures 1(a)\&(b) in Appendix B). The trailer has two side concession doors measuring 12' x 4' that swing up, and two doors in the rear. It includes a FlexLink conveyor loop. Surrounding it are two workcells each containing a PUMA 560 robot and one of them includes a DENFORD NC machine. A SUN SPARCstation 20 and an IPX are the integrators for design-manufacturing information flow, work sequence, feed-back control and material handling. Space is tight within the trailer. All controllers and computers are stacked into two 6' racks. Figure 1 shows a schematic trailer layout. Students and instructors stand around the trailer on the outside to work on programming and teaching robots and NC machines. All equipment and work areas are placed at waist-level for easy viewing and access. When the CIM environment is in automated mode, the trailer is safe-guarded by a surrounding light fence.

Flexibility and environmental control of more than one workcell are managed through the FASTech manufacturing control software. The configurations for the hierarchical control 
constitute (a) cell level control for each of the workcells (Levels 1-3 in Figure 2), (b) supervisory control by the SUN SPARCstation 20 over the cell computer SUN IPX. Refer to the cross-over line between Cell\#1 and Cell\#2 in Figure 2. Students in the course will collaboratively design and manufacture one or a class of products.

\section{Figure 1: Layout of the CIM on Wheels}

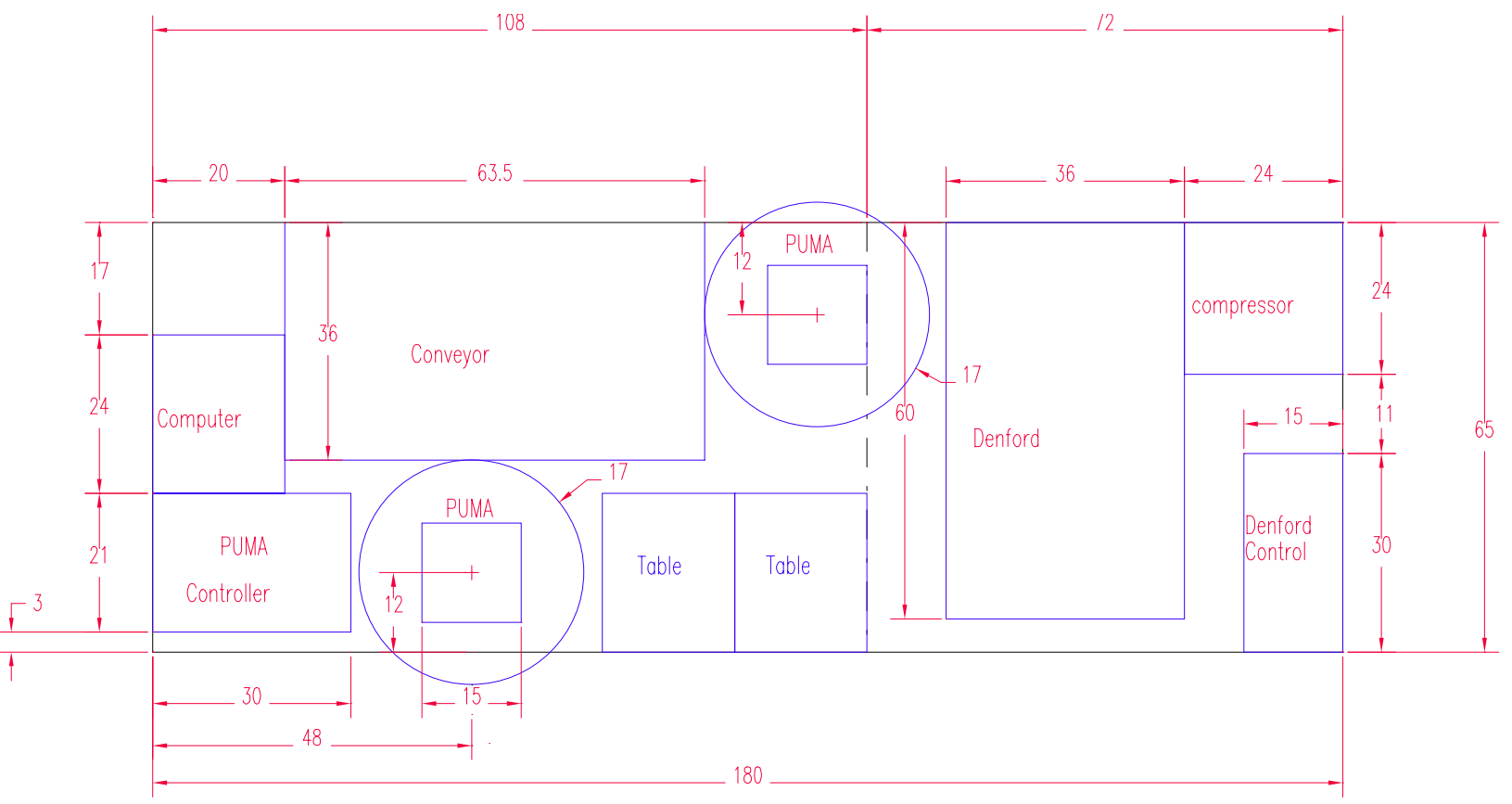

\section{Student Project}

The students are given a set of functional requirements to conceive, design, plan manufacturing processes, design and fabricate fixtures, plan process sequences, and manufacturing the part with as much automation as possible under tight budgetary constraints.

\section{A. Development Process}

For the Fall 1995 CIM class, their functional requirements are: design and fabricate a product usable by everyone, everyday. The entire CIM class is responsible for the one product. The class decided to design and fabricate a desk-top clock set with a holder for business cards. Figure 2 in Appendix B shows the product. Figure 3 in Appendix B shows the $2^{\text {nd }}$ generation product for Fall 1996 CIM class which has improved features from the first generation product. The students are asked to elect a manager. The instructor is the CEO of a QC- 1 company. The students then form teams of 2 or 3 depending on class size and each team picks a team leader 
responsible for passing the proper output to the downstream operations and adhering to the standards used by groups from upstream operations. As a class, they determine the design of the product. They then list a set of sub-projects and divide the class into an appropriate number of teams to cover all the modules. As teams, they meet among themselves. Group meetings are scheduled and extra class meetings are set up for the entire class. They write the plans for manufacturing processes. Figure 3 shows the organization of teams management. Interactions are shown as arrows.

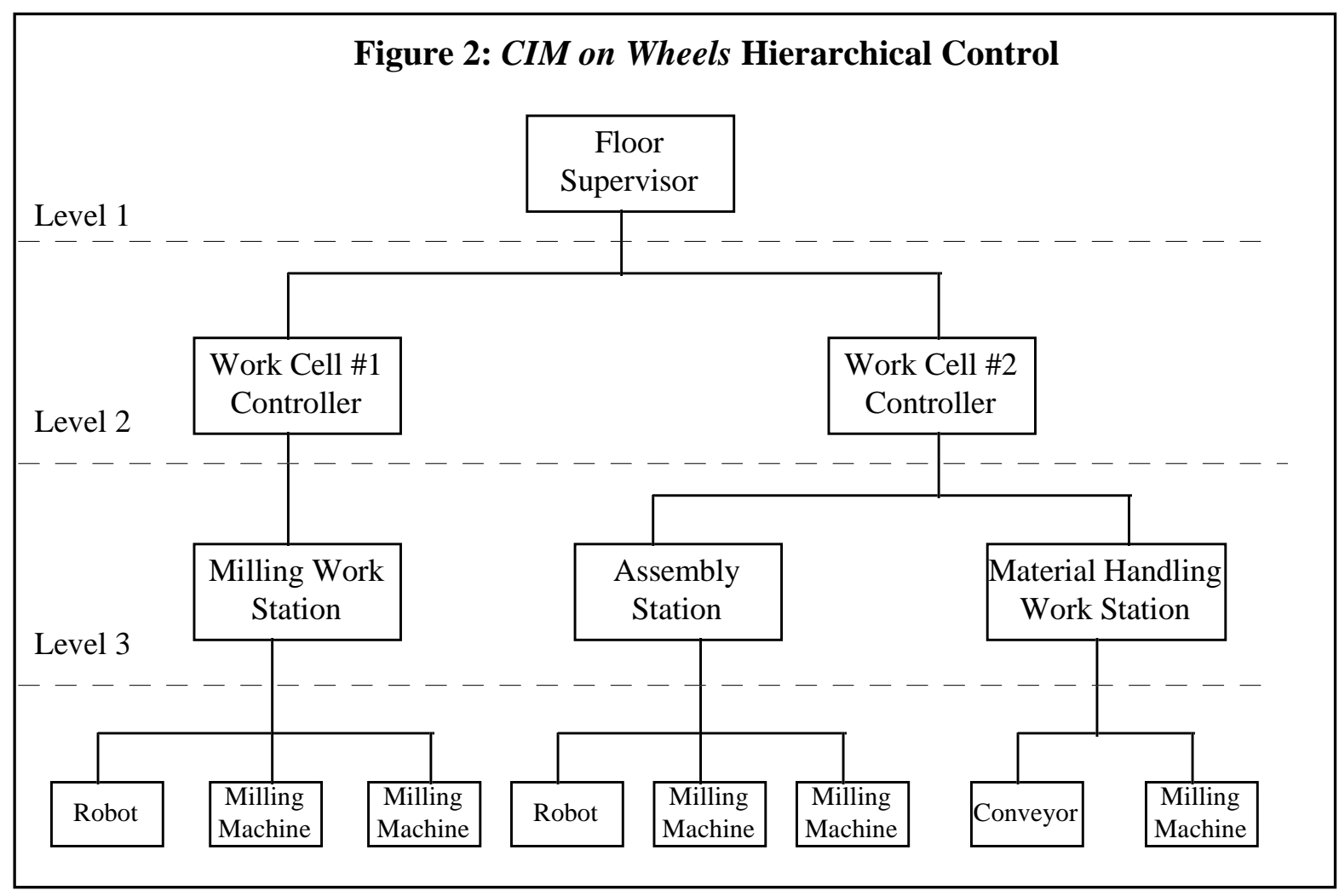

\section{B. Fabrication Phase}

After all the part and fixtures are designed, processes are selected and operation sequences are defined, the students fabricate the necessary pre-production raw material (e.g. cut the raw material to a proper shape) and fixtures. They then write the robot programs and generate NC programs through CAD-CAM and coordinate the sequential or parallel operations of all project modules.

\section{Equipment and Workstation Communication Phase}

For input / output (I/O) from robots, NC machines and PLC, the requirements are first listed by the entire class. The layout and control teams assign port numbers to each $\mathrm{I} / \mathrm{O}$ and posts the list for use by all groups. Since the workpart is transferred from one station to the next, part orientation and proper fixturing are of utmost importance. The entire manufacturing system is controlled by a control flowchart written under CELLworks software from FASTech Integration, Inc. For identification purposes, the robots are called Romeo and Juliet, the NC machine is Miller, the conveyor is called Roadrunner. There are 3 pallet stations on the conveyor loop, one at each robot Romeo, Juliet and Robota (manual station). The PLC is used to control which 
pallet carrying a specific workpart is to be locked at what time, at which station and when it is to be released. Parts are ordered through turning signals ON or OFF by the robots whenever they are needed. Workpart presence is detected by sensors located at the pallet stations. The flow of work material, sequence of operations (serial or parallel), activation of robots and NC machine are all done by the CELLworks flowchart running on the SUN SPARCstations. The arrows in figure 3 show the schematic flow of the control processes.

\section{Figure 3: Project Organizational Chart}

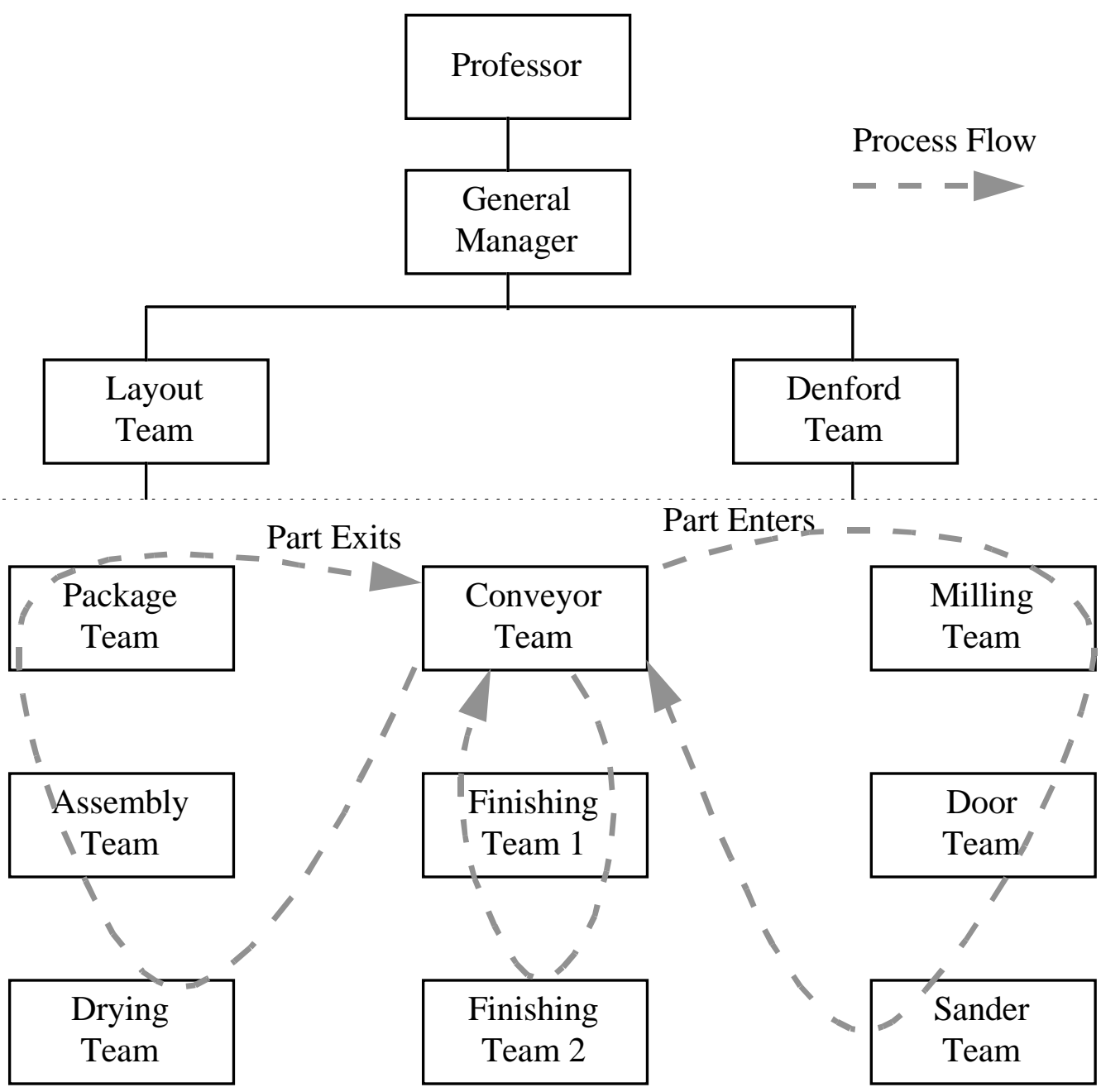

\section{Intra- and Inter-Team Communication}

Besides proper design and technical procedures, the key to a class project of this size is communication and cooperation. Paraphrased comments from the student includes: "we never expected that we would have such problems with miscommunication", "this project gave us a lot of insight into the various components of CIM", "it gave us a good opportunity to learn to work with each other", " this is the only course that allows us to put our hands into real problematic 
situations and how they can or cannot be solved". Pictures in Figure 4 in Appendix B show the students at work. 


\section{E. Oral Presentations to Fellow Students, VIP's from GMI}

The students are required to give formal and informal presentations to each other in class and to professors and administrators, including the president of the university. They describe their designs, plans and fabricated products and programs. The president, Dr. J. John, has been very supportive of their efforts by consistently attending their presentations whenever possible. By relating and teaching others of their project or module of the project, the students understand the material covered in class to a much deeper extent. "You really get to know the stuff when you describe it to others", said one student.

\section{Culmination of Efforts}

The trailer was towed to the SME-AutoFACT Exhibition at Cobo Hall, Detroit Michigan, November 12-14, 1996. The students had to describe not only their portion of the project, but also the project in its entirety. They ran all the equipment, and produced desk-top sets and gave them away at the show. There were steady crowds at the trailer throughout the 3 days. Much enthusiasm was generated by exhibit attendees. Numerous positive comments were conveyed to the students as well as the authors. Visitors were very enthusiastic about the CIMoW concept of students conducting the projects, and presenting their work and ideas to other students and engineers at the show. Louis Papp, director of SME Educational Foundation asked to contract the $\boldsymbol{C I M o} \boldsymbol{W}$ to be taken to Ontario, Canada for educational purposes. Dan Maas, an executive director at NCMS expressed that $\boldsymbol{C I M o W}$ is an extremely powerful educational tool for integrating technology. Paul Koontz is already making arrangements for an article about $\boldsymbol{C I M o W}$ in a national educational journal. One student was promised a job at the exhibition. There were a number of requests for appearance of the CIM on Wheels in Detroit-Flint areas. CIMoW can also furnish an up-to-date outreach media for attracting and motivating minority, women and perhaps handicapped students into the engineering programs.

\section{Scheduling Usage of CIMoW}

Careful scheduling of the CIMoW usage will be required for efficient equipment sharing. Lab periods at GMI will be scheduled alternately with short courses or seminars to ensure availability of $\boldsymbol{C I M o W}$. External trips to high schools, middle schools, conferences will have to be planned in advance.

\section{Acknowledgement}

Equipment has been supported mainly by GMI matching funds, NSF Grant No. DUE9251700, SUN Microsystems, Inc.EDUD-US-933033, FASTech Integration, Flex-Link Conveyor Systems, Denford Computerized Machines \& Systems, Inc., Staubli Unimation, Inc., TRW, 80/20 Inc.- Industrial Erector Set and others. The authors would like to thank the entire CIM class (Fall, 1996) student body and the class manager Michael Hoag for their effort and extra time, Professor William White for assistance in designing and fabricating the pallets and coordinating the towing and moving of the trailer.

\section{Bibliography}

[1] "The Skills Crisis in the American Workforce", Carnevale, A., FOCUS National Center for Manufacturing Sciences, pg. 1, August, 1991. 
[2] Michael Mills' quotation from Bedworth, D., Henderson, U., and Wolfe, P. M., Computer Integrated Design and Manufacturing, McGraw-Hill, 1991.

[3] NCMS Members Share New Training Models", R. Lang. FOCUS National Center for Manufacturing Sciences, pg. 4, August, 1991.

[4] Okamura, S., "Engineering Education in Japan," International Journal of Engineering Education, Vol. 9, No. 1, pp. 6-15, 1993.

[5] Yamazaki, K., Miyazawa, S., "A Development of Courseware for Mechatronics Education,” International Journal of Engineering Education, Vol. 8, No. 1, pp. 61-70, 1992.

[6] El Maraghy, Hoda A., "Computer Integrated Manufacturing Education and Research", Journal of Manufacturing Systems, Vol. 6, No. 4, pp 329, 1987.

[7] Report from Oak Ridge Centers for Manufacturing Technology, Contact: 4USA@ornl.gov.

[8] Wenk, Jr., "In Propelling Change and Altering Our Belief Systems and Culture, Technology has Joined Religion, Tradition, and Family in the Scope of its Influence", ASEE Prism, pp. 26-28, December, 1996

\section{Biographical Sketches}

LUCY SIU-BIK KING received her Ph.D. Degree, BioMathematics from University of California, Berkeley, 1972. She has been a full professor in IMSE at GMI Engineering \& Management Institute, Flint, MI, since Summer, 1991. She received federal and private grants to set up a CIM environment in the lab and in a trailer (called the CIM on Wheels) and taught CIM and Robotics using the environment. Her recent research interests lies in the optimization modeling and methods on decision processes as applied to automated fixturing.

JIAN EDWARD ZHANG received his M.S.M.E. Degree, Beijing Institute of Technology, Beijing, PRC, 1988. He worked as an engineer at Beijing Internal Combustion Engine Plant for 3 years in China. Subsequently, he worked for Singapore Far East Computer Pte. Ltd. for four years as an engineer, promoted to technical manager. He is a graduate student in Manufacturing Systems Engineering at GMI Engineering \& Management Institute, Flint, MI. His strength is in CAD/CAM/computer integration.

\section{Appendix A: IMSE-480 Computer Integrated Manufacturing Course Description}

Study the current status of CIM, with definition, case studies, citing obstacles and future trends and development. Some key components of CIM and hierarchy of operation in a manufacturing facility are studied and correlated. They include CAD-CAM link, numerical control, automation, production and manufacturing control through proper communication and computer supervisory control, robotics control, process planning. Short summary of planning, implementation and managing of a CIM environment will also be covered. Experiments and projects on creating a CIM environment using computer supervisory control will be conducted by the students. Prerequisite: ME-312, Introduction to Computer Aided Design 
Appendix B: Pictures of Products and Students
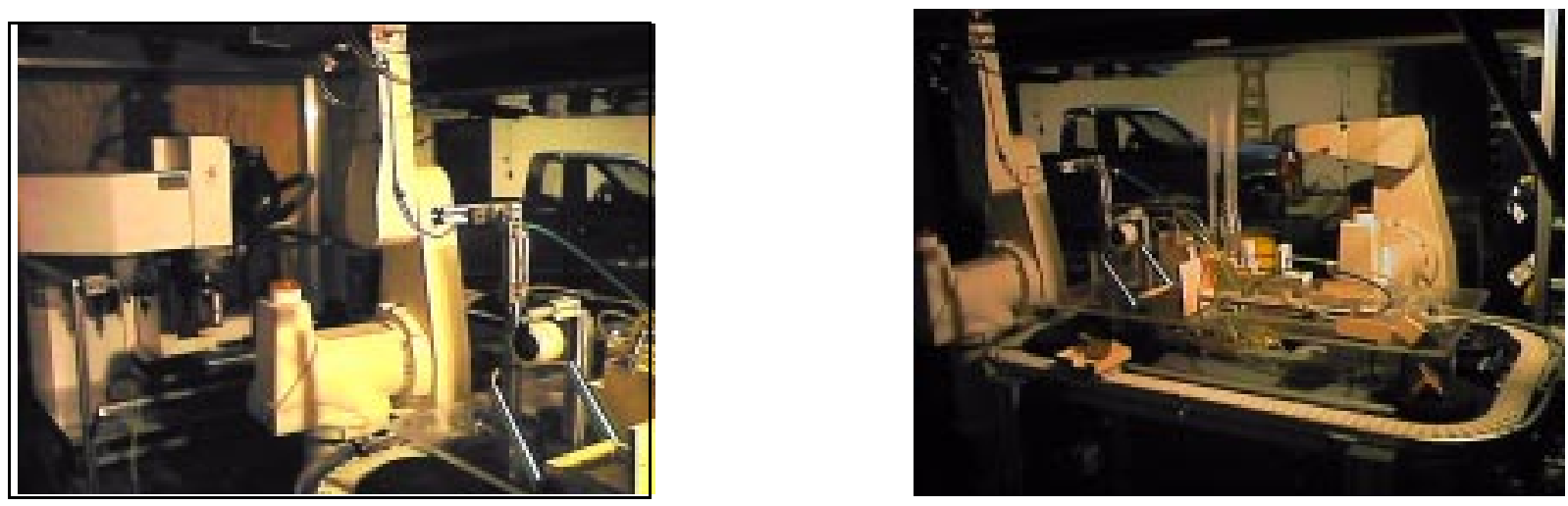

(a)

Figure 1: Inside Views of the Trailer

(b)
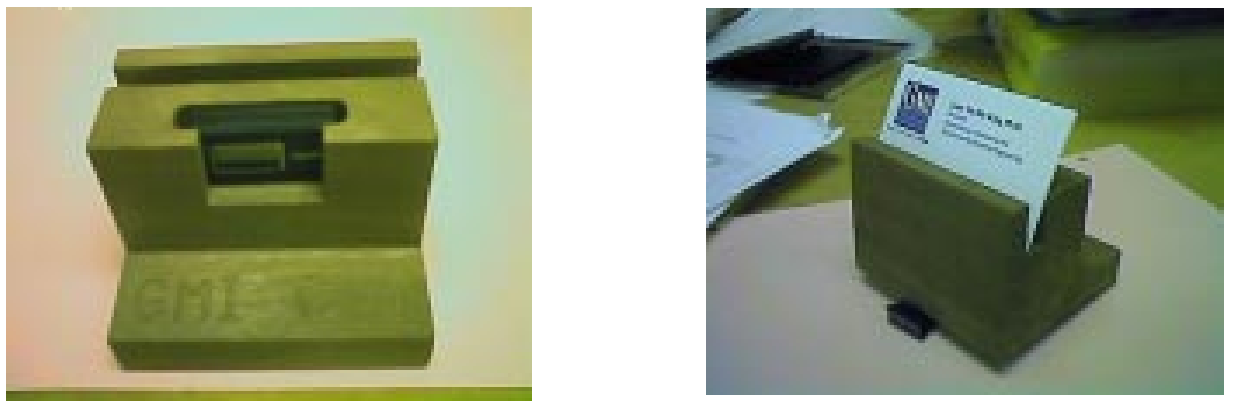

Figure 2: First Generation Desk Top Set
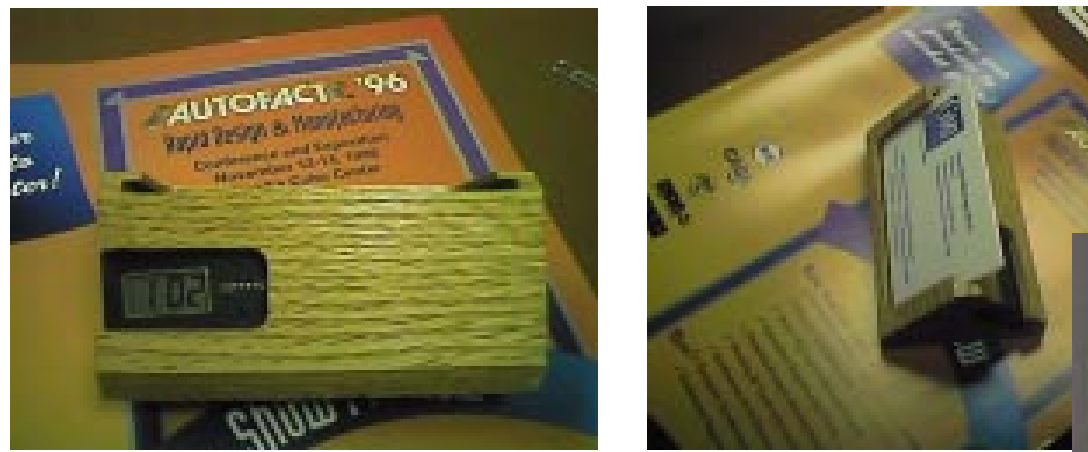

Figure 3: Second Generation Desk Top Set

Figure 4: Students at Work
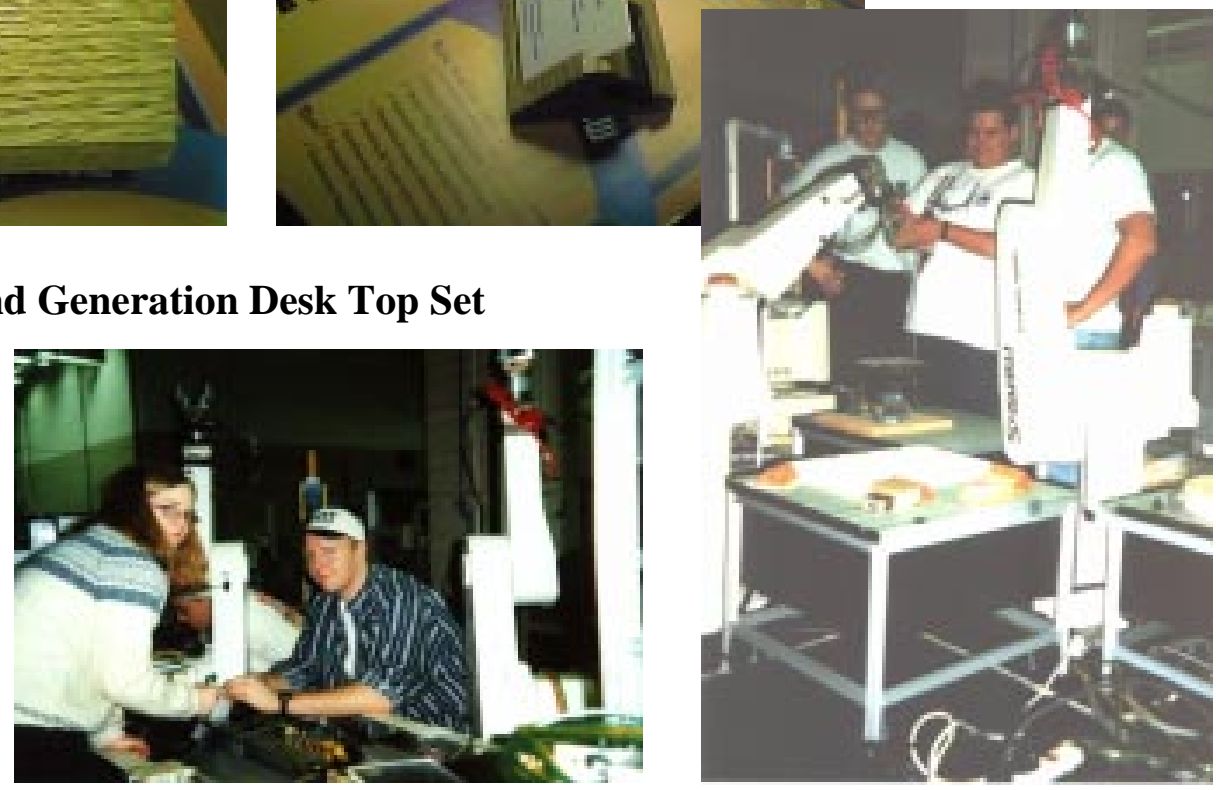